\title{
Relaxation Behavior of Residual Stress on Deck-to-Rib Welded Joints by Fatigue Loading in an Orthotropic Bridge Deck
}

\author{
Wen Zhong ${ }^{1}$, You-liang Ding ${ }^{1 *}$, Yong-sheng Song ${ }^{2}$, Fang-fang Geng ${ }^{3}$ \\ ${ }^{1}$ Key Laboratory of Concrete and Prestressed Concrete Structures of Ministry of Education, Southeast University, 210096, \\ Nanjing, China \\ 2 School of Architecture Engineering, Jinling Institute of Technology, 211169 Nanjing, China \\ ${ }^{3}$ School of Architecture Engineering, Nanjing Institute of Technology, 211167 Nanjing, China \\ *Corresponding author, e-mail: civilchina@hotmail.com
}

Received: 21 April 2019, Accepted: 14 September 2019, Published online: 18 November 2019

\begin{abstract}
To accurately evaluate the influence of the actual tension and compression state and stress ratio at the deck-to-rib welding seam position on the fatigue life of a bridge deck, this paper establishes a coupled stress analysis model that considers the welding residual stress and vehicle stress. Taking the Jiangyin Bridge as an example, a qualitative analysis of the fatigue life under the vehicle load and residual stress field is carried out using the proposed method. A case analysis showed that when the residual tensile stress in the welding seam position is superimposed on the mainly tensile cyclic vehicle load stress, the longitudinal stress relaxation exceeds the peak vehicle load stress; significant longitudinal stress relaxation occurred, while the transverse stress relaxation is not significant. However, when the residual tensile stress is superimposed on the mainly compressive cyclic vehicle load stress, the relaxations of both the longitudinal and transverse stresses are not obvious. Compared with the stress state of the welding point under the action of only the vehicle stress, when the coupling effect of the residual stress and vehicle stress is considered, i.e., the loading condition, the fatigue stress state of the weld point has undergone an essential change under cyclic compressive stress, that is, the compressive stress state that does not require a fatigue check is changed to the tensile stress state. Although the fatigue state of the tensile stress cycle condition has not changed, the fatigue life is reduced by varying degrees under either the compressive or tensile condition.
\end{abstract}

\section{Keywords}

orthotropic steel deck (OSD), stress relaxation effect, deck-to-rib welding details, welding residual stress, coupling stress

\section{Introduction}

The orthotropic steel deck (OSD) is the preferred deck structure for long-span bridges. However, with the increase in the service life of bridges, fatigue cracks in steel bridge decks have emerged, such as on the Humen Bridge (built in 1997), Jiangyin Yangtze River Bridge (built in 1999) and Second Nanjing Yangtze Bridge (built in 2001). These cracks occurred only approximately 10 years ago, taking place after they were opened to traffic and causing major economic losses and adverse social impacts [1-3]. Therefore, the anti-fatigue design of OSDs is essential. Among the various fatigue distresses that occur in steel bridge decks, the most common is the fatigue cracking of the deck-to-rib welded details [4-5]. For the anti-fatigue design of this type of welding detail, the stress range-number of cycles (S-N) curves based on typical welded structures are commonly used in domestic and foreign codes [6-8]. The main factor of the fatigue design is thus the stress amplitude, and the residual stress of the weld, the relaxation effect, and their influence on the stress ratio are not considered. This is mainly because there is a high residual stress at the welding seam, and the true stress at the welding seam may approach or exceed the yield strength of the material under external loads, resulting in only a small effect of the stress ratio on the fatigue life [9]. In addition, fatigue strength theory states that a tensile average stress acts to reduce the fatigue life, while a compressive average stress is beneficial to the fatigue [10]. In this regard, China's latest version of "Code for Design of Steel Structure of Railway Bridge" [11] used $R=-1$ as the critical value to divide the fatigue stress state of the welded components into a mainly tensile stress state of the tensile-tensile condition and a mainly compressive stress state 
of the tensile-compression condition. When $R \leq-1$, the fatigue stress state is the tensile-compressive stress state dominated by the tensile stress; in this situation, a fatigue check should be performed. When $R<-1$, the fatigue stress state is the tensile-compressive stress state dominated by the compressive stress; in this stress state, the influence of the compressive stress on the cumulative fatigue damage is completely not considered. However, for the steel deck-torib welding details, the real stress level of the welding seam position is very different when only considering the vehicle stress versus considering the coupling effect of the vehicle stress and the welding residual stress. The main reason is that after the welding residual stress is considered, the stress ratio $R$ at the welding seam position changes greatly, resulting in essential changes in the tensile and compressive states of the weld detail. In addition, a stress relaxation effect will be generated after the high residual stress at the weld is superimposed on the external load stress, and the magnitude of the stress relaxation will also have a certain degree of influence on the true stress level of the welding details. Therefore, the traditional steel bridge deck welding detail fatigue design adopts the S-N curve method, which cannot effectively reflect the true welding residual stress level of the structure; when applied to an actual steel bridge structure, the fatigue life tends to be overestimated. Domestic and foreign scholars are working hard to develop more accurate fatigue life calculation methods [12-14].

In recent years, some scholars carried out research on the influence of the stress ratio and welding residual stress on the fatigue life of OSDs. Zhang et al. [15] noted that under vehicle loads, the cyclic stress ratio at the position of the deck-to-rib welded joints in an OSD is much less than -1 , so an S-N curve considering the cyclic stress ratio should be adapted in the fatigue life analysis. However, the calculation of the stress ratio in this paper only considers the vehicle load, and whether the true stress ratio at the weld seam under the coupling of the welding residual stress and vehicle stress is much less than -1 is open to question. Cui [16] proposed a fatigue life calculation method that considers the influence of the welding residual stress. First, a simplified calculation method is established for the coupling stress between the welding residual stress and vehicle stress; then, the fatigue life is calculated using a strain energy-based method. However, in the calculation of the coupling between the welding residual stress and vehicle stress, elementary beam theory is assumed, and a simple nonlinear superposition of the welding residual stress and vehicle stress is employed. Therefore, the elastic-plastic stress redistribution phenomenon due to high-magnification welding residual stress coupling with the vehicle stress can only be qualitatively discussed. The welding residual stress relaxation cannot be quantitatively calculated, and the actual tensile and compression states of the fatigue stress and stress ratio at the welding seam, in turn, cannot be accurately assessed. Therefore, although the calculation results show that the welding residual stress has an effect on the fatigue life of the OSD, its mechanism cannot be explained.

The above works opened up new ideas for the study of fatigue life calculation methods for OSDs. To accurately evaluate the true tensile and compressive states of the welding seam position and study the influence of the stress ratio and welding residual stress on the fatigue life, it is necessary to quantitatively calculate the relaxation effect of the welding residual stress under a vehicle load. For this reason, based on the coupling of the birth-death element technology and thermal-structural coupling analysis using ANSYS finite element software, a coupled stress analysis model of residual stress and vehicle stress of deck-torib welding joint is established, and a refined calculation method considering the welding residual stress and relaxation effect is proposed. The calculation method is used to parameterize the coupled model for different external load conditions and deck thicknesses, and the relationship between the residual stress relaxation and the initial residual stress and external load is summarized. Taking the welding details of the deck-to-rib of the OSD of the Jiangyin Yangtze River Bridge as an example, the refined calculation method is used to calculate the true stress spectrum of the welding details for different transverse locations of vehicles and obtain fatigue parameters such as the stress ratio and equivalent stress magnitude under the action of the welding residual stress and vehicle load coupling. A qualitative analysis of the impact of vehicle loads and residual stresses on the fatigue life was carried out. The relevant conclusions provide a basis for an in-depth research study of a method for calculating the fatigue life as affected by the stress ratio and welding residual stress.

\section{Analysis method of the welding residual stress relaxation effect}

\subsection{Analytical model}

After the residual stress at the welding seam is superimposed on the external load stress, the coupled stress tends to exceed the yield strength of the material, causing the partial elastic strain to be transformed into plastic deformation 


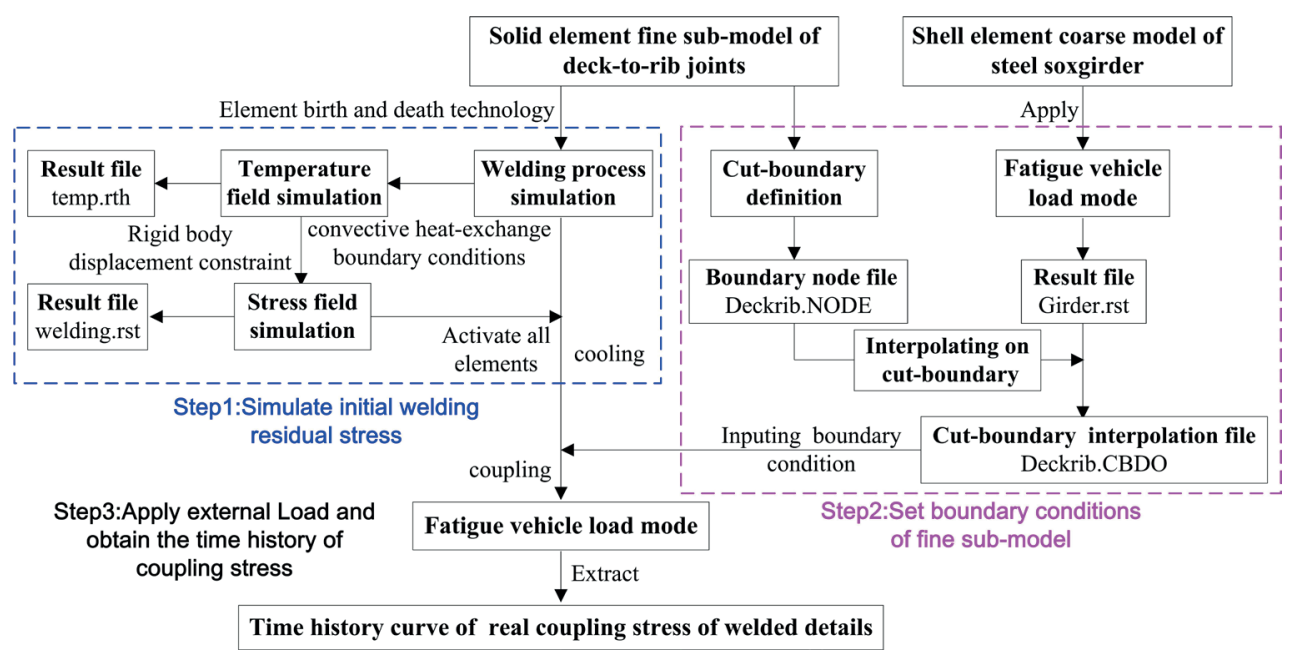

Fig. 1 Flow Chart of the Coupling Stress Analysis of the Welding Residual Stress and Vehicle Load Stress

and resulting in stress release and the redistribution of the residual stress in the plasticized zone after unloading. This result in the final coupling stress being less than the initial residual stress, that is, the welding residual stress has a relaxation effect under cyclic loading [17, 18]. From the aforementioned description, it can be seen that the value of stress relaxation is the difference between the initial residual stress and the final coupling stress. To quantitatively calculate the relaxation effect of the welding residual stress under a vehicle load, it is necessary to accurately evaluate the time-history variation of the coupling of the residual stress during the loading and unloading cyclic stress process. To this end, this paper establishes a refined stress analysis model of the steel bridge deck welding residual stress coupled with the vehicle loading stress; comprising three steps (Fig. 1): 1. a thermal-structural coupling method is developed for simulating the initial welding residual stress production process; 2 . the submodel method is used to set the displacement boundary condition of the deck-to-rib refined submodel; and 3. the same fatigue vehicle model load is applied on the top surface of the submodel and the top surface of the coarse model to finally obtain the true coupling stress time-history of the welding details.

Step 1. Use thermal-structural coupling method for simulating the initial welding residual stress production process. The specific steps are as follows: (1) Establish a deck-to-rib solid element coupling analysis fine submodel (Fig. 2), hereinafter abbreviated as a submodel. Taking the Jiangyin Yangtze River Bridge as an example, the 8-node SOLID185 solid element provided by ANSYS is used to perform a fine finite element simulation on the deck, longitudinal rib and weld structure in $1.5 \mathrm{U}$ ribs. The submodel size and welding seam details are shown in Fig. 2(b). The minimum unit size of the welding seam and heat affected zone is $0.5 \mathrm{~mm}$; the largest unit size far away from the welding seam is $8 \mathrm{~mm}$. The model materials in this paper are all Q345 steel (the yield stress is $345 \mathrm{MPa}$ ) and the thermal and mechanical parameters of Q345 steel at different temperatures are provided in Table 1 [19-21]. The welding rod

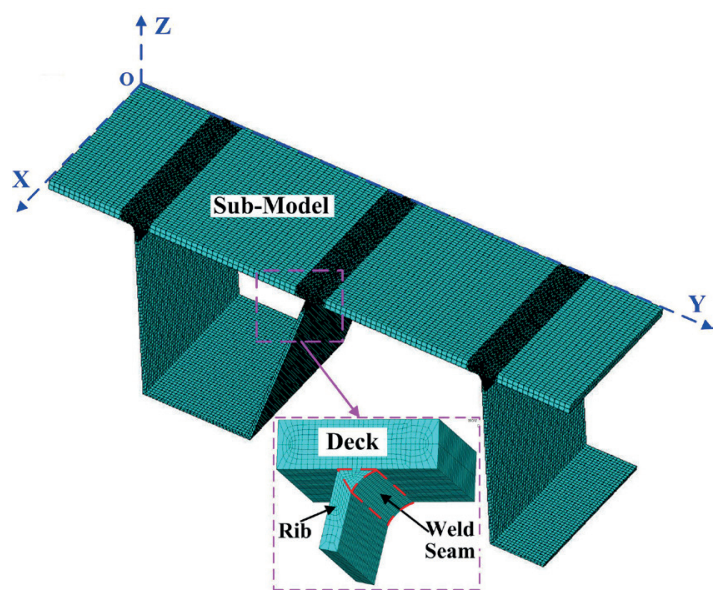

(a)

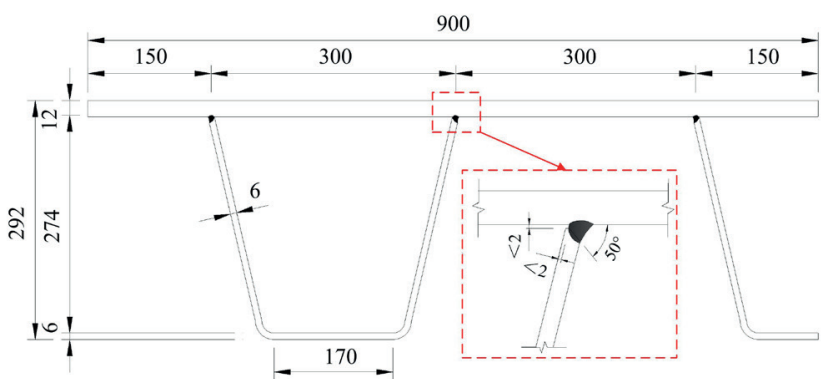

(a)

Fig. 2 Solid element coupling analysis fine submodel of the deck-to-rib welded details: (a) finite element model; (b) cross-section diagram of the submodel (unit: $\mathrm{mm}$ ) 
Table 1 Temperature-dependent properties of thermal and mechanical parameters of Q345 steel

\begin{tabular}{|c|c|c|c|c|c|c|c|c|}
\hline $\begin{array}{c}\text { Temperature } \\
\left({ }^{\circ} \mathrm{C}\right)\end{array}$ & $\begin{array}{l}\text { Thermal } \\
\text { conductivity } \\
\left(\mathrm{W} / \mathrm{m} \cdot{ }^{\circ} \mathrm{C}\right)\end{array}$ & $\begin{array}{l}\text { Density } \\
\left(\mathrm{kg} / \mathrm{m}^{3}\right)\end{array}$ & $\begin{array}{l}\text { Specific heat } \\
\left(\mathrm{J} / \mathrm{kg} \cdot{ }^{\circ} \mathrm{C}\right)\end{array}$ & $\begin{array}{l}\text { Poisson's } \\
\text { ratio }\end{array}$ & $\begin{array}{c}\text { Linear expansion } \\
\text { coefficient } \\
\left(10^{-5} /{ }^{\circ} \mathrm{C}\right)\end{array}$ & $\begin{array}{c}\text { Elasticity } \\
\text { modulus (GPa) }\end{array}$ & $\begin{array}{l}\text { Yield stress } \\
(\mathrm{MPa})\end{array}$ & $\begin{array}{c}\text { Tangent } \\
\text { modulus }(\mathrm{GPa})\end{array}$ \\
\hline 20 & 50 & 7820 & 460 & 0.28 & 1.1 & 205 & 345 & 2.05 \\
\hline 250 & 47 & 7700 & 480 & 0.29 & 1.22 & 187 & 280 & 1.87 \\
\hline 500 & 40 & 7610 & 530 & 0.31 & 1.39 & 150 & 213 & 1.5 \\
\hline 1000 & 30 & 7490 & 670 & 0.4 & 1.34 & 20 & 73 & 0.2 \\
\hline 1500 & 35 & 7350 & 660 & 0.45 & 1.33 & 2 & 13 & 0.02 \\
\hline 2000 & 45 & 7300 & 750 & 0.48 & 1.32 & 1.5 & 1 & 0.015 \\
\hline 3000 & 50 & 7100 & 800 & 0.5 & 1.31 & 0.1 & 1 & 0.001 \\
\hline
\end{tabular}

is E50 type, and its thermophysical and mechanical parameters are the same as Q345 steel. (2) Perform a submodel thermal analysis. (3) The constraint of not producing rigid body displacement and not seriously hindering free deformation is applied to the deck to simulate the action of the peripheral members, and then the thermal analysis results are applied as a body load to the submodel. (4) Perform a submodel stress analysis and obtain the longitudinal and transverse residual stress distribution curves of the deckto-rib weld toe position. There are some assumptions were adopted in the process of stress field analysis: a) welding materials are subject to von Mises yielding criteria; b) the behavior in plastic zone is subject to the plastic flow rule and hardening rule; c) elastic strain, plastic strain and temperature strain are inseparable; and d) temperature-dependent mechanical properties, stress and strain change linearly in small time increments.

Step 2. The submodel method is used to set the displacement boundary conditions of the deck-longitudinal-rib fine submodel. The specific sub-steps are as follows: (1) the Shell63 elastic shell element is used to establish the overall steel box girder shell element coarse model (Fig. 3), referred to as the coarse model in the text that follows; the total number of units is 91,090. The length of the steel box girder along the bridge is taken as five partition spacings; the width is $32.5 \mathrm{~m}$, the length of the bridge segment is $18.75 \mathrm{~m}$, and the thickness of the diaphragm plate is $14 \mathrm{~mm}$. (2) An overall structural stress analysis is carried out by applying the fatigue vehicle load (Fig. 9) to the coarse model. The boundary condition is the simple support constraint along the bridge length on both sides, and the displacement response of the boundary of the submodel is calculated. (3) Then, the displacement response obtained in the previous step is used as the boundary condition, and it is automatically applied to the corresponding position of the submodel by linear interpolation.

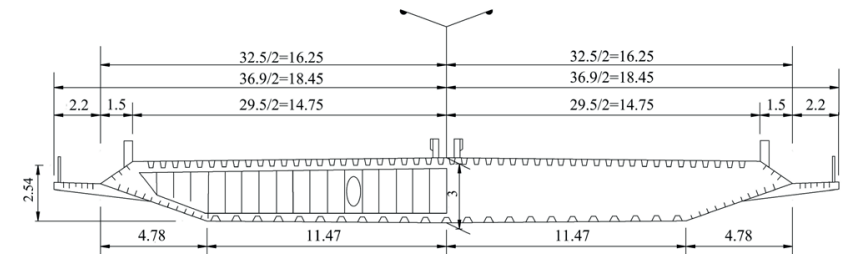

(a)

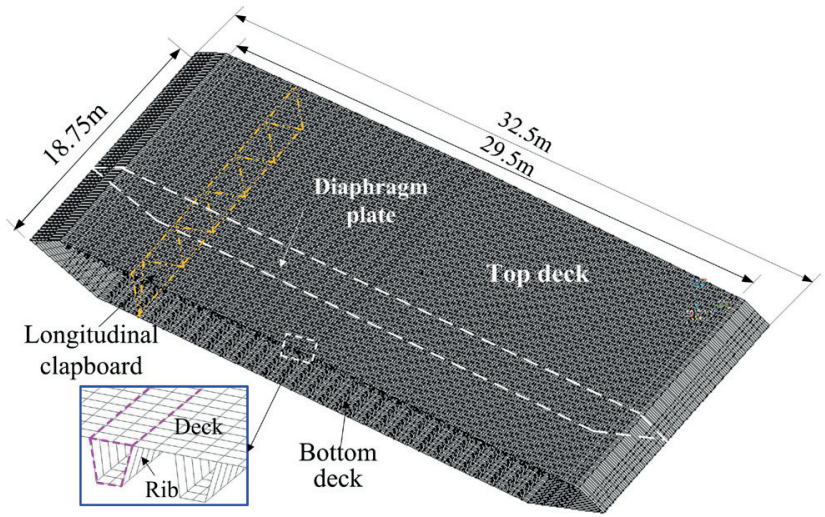

(b)

Fig. 3 Shell element coarse model of a steel box girder: (a) cross section of a main girder of the Jiangyin bridge; (b) finite element model (unit: m)

Step 3. The same fatigue load on the deck of the coarse model is applied to the deck of the submodel (Fig. 4) to obtain the true coupled stress time history of the weld detail. The cyclic plasticity constitutive model of Q345 steel [22-24] is adopted in the finite element modeling of weld-induced residual stress relaxation under fatigue loading. The plasticity model of the steel under cyclic loading is defined using the initial yielding condition, plastic flow rule, and hardening rule.

\subsection{Model verification}

Subsection 2.2 verifies the accuracy of the established residual stress relaxation effect analysis model by the following three aspects. The first aspect is to check the rationality of the heat source application in the temperature 


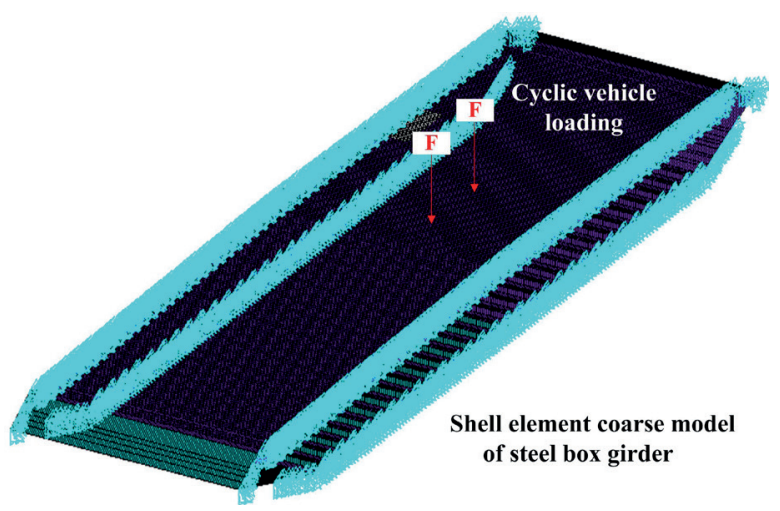

(a)

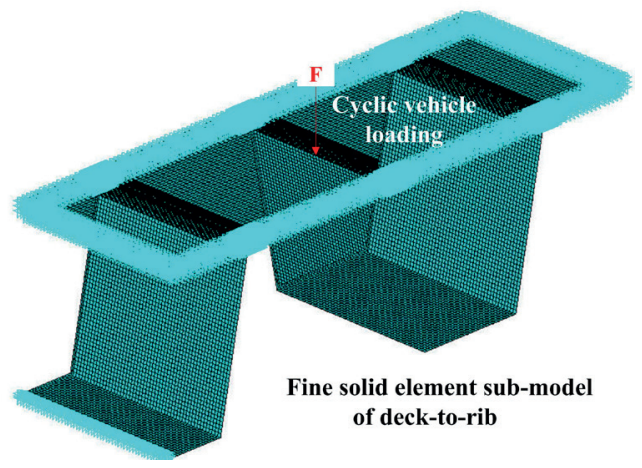

Fig. 4 Vehicle loading application: (a) shell element coarse model; (b) solid element fine submodel (unit: $\mathrm{m}$ )

field simulation, the second is to compare the numerical simulation results of the welding residual stress with experimental data, and the third is to compare the calculation accuracies of the submodel and the coarse model on the vehicle stress under a vehicle load.

\subsubsection{Temperature field simulation results}

The temperature field analysis of the welding process is a transient thermal analysis with an initial temperature setting of $20^{\circ} \mathrm{C}$. In this paper, the finite element life and death unit technology is used to simulate the melting-solidification process of the weld, and the temperature load is applied in the form of a heat generation rate $(H G E N)$. During the welding process, the weld seam elements are killed at the beginning. Then, the killed elements are gradually activated in the welding process to simulate weld seam metal filling. At the same time, the heat generation rate (HGEN) is imposed on the activated weld seam elements to simulate a moving heat source, which is calculated by Eq. (1).

$$
H G E N=(\eta \times U \times I) /(A \times v \times d t)
$$

In Eq. (1), $H G E N$ is the heat generation rate (watt per cubic meter); $\eta, U$ and $I$ is the heat efficiency, voltage, and electric current, respectively, in the welding process;
$A$ is the cross-sectional area of weld seam; $v$ is the welding velocity; and $d t$ is the welding time for each weld seam element length. Parameters $\eta=0.8, U=30 \mathrm{~V}, I=320 \mathrm{~A}$, $v=0.01 \mathrm{~m} / \mathrm{s}$ and $d t=0.2 \mathrm{~s}$ are applied in the simulation [14].

Fig. 5 shows a temperature change cloud diagram of the model welding and cooling process. The length of the welding seam is $300 \mathrm{~mm}$, the welding speed is set to $10 \mathrm{~mm} / \mathrm{s}$, the welding time of each welding seam is $30 \mathrm{~s}$, and the cooling time is $30 \mathrm{~s} \sim 2400 \mathrm{~s}$. The convection boundary condition is applied on all surfaces with a convection film coefficient $15 \mathrm{~W} /\left(\mathrm{m}^{2} \cdot{ }^{\circ} \mathrm{C}\right)[20]$.

Fig. 5(b) shows the distribution of the temperature field of the weldment section at $30 \mathrm{~s}$. The area encircled by the black dotted line in the figure is the area with a temperature higher than the melting point. The shape of the area is close to the shape of the welding seam in Fig. 2(b),

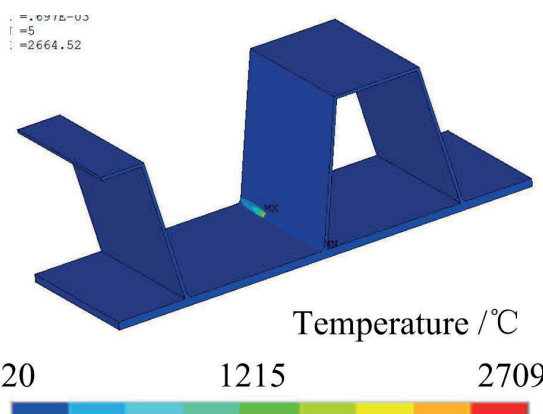

(a)

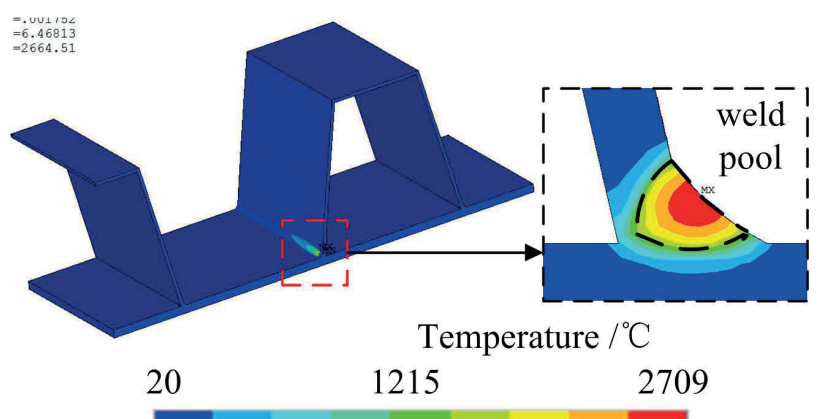

(b)

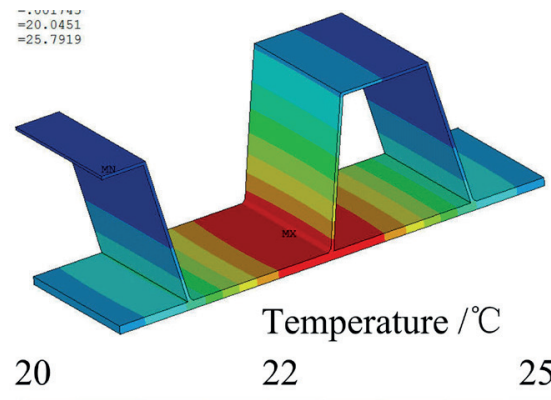

Fig. 5 Temperature distribution in the thermal simulation: (a) 10s; (b) $30 \mathrm{~s}$; (c) $2400 \mathrm{~s}$ (unit: ${ }^{\circ} \mathrm{C}$ ) 
indicating that the applied model heat source is reasonable. During the entire welding temperature field simulation process, the maximum temperature around the welding seam is approximately $2700{ }^{\circ} \mathrm{C}$. Although the temperature of each point on the test piece changes with the movement of the heat source, the temperature field always maintains a stable form.

\subsubsection{Stress field simulation results}

The longitudinal and transverse welding residual stress distribution results of the intermediate welds of the submodel are shown in Fig. 6. Fig. 6(a) is a comparison of the longitudinal residual stress numerical simulation results of this paper and experimental data [25-27]. The numerical model in this paper adopts the same welding detail and material (Steel Q345) as the test specimen in the literature $[26,27]$, whereas the geometry size of them is different. The numerical simulation model is built referencing the actual size of the Jiangyin Bridge. The thickness of the top deck is $12 \mathrm{~mm}$, and the thickness of the ribs is $6 \mathrm{~mm}$. In the literature [26], a scale specimen with a top deck thickness of $8 \mathrm{~mm}$ and a ribs thickness of $4 \mathrm{~mm}$ is used in experiment and proportion is 1:1.5. In the literature [27], a full scale specimen with a top deck thickness of $10 \mathrm{~mm}$

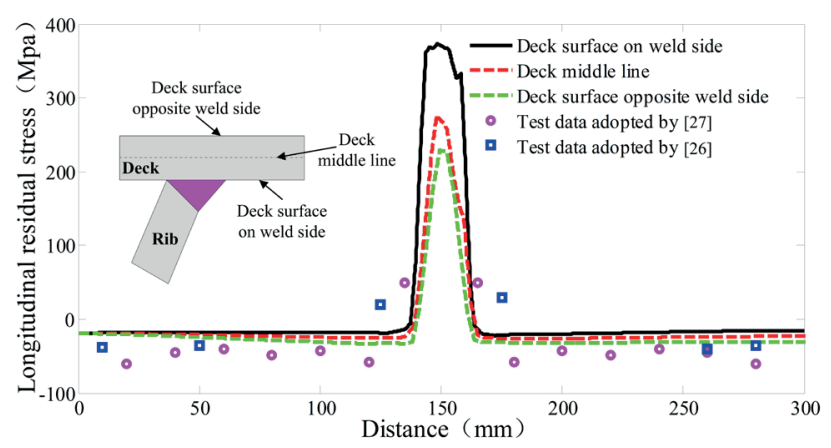

(a)

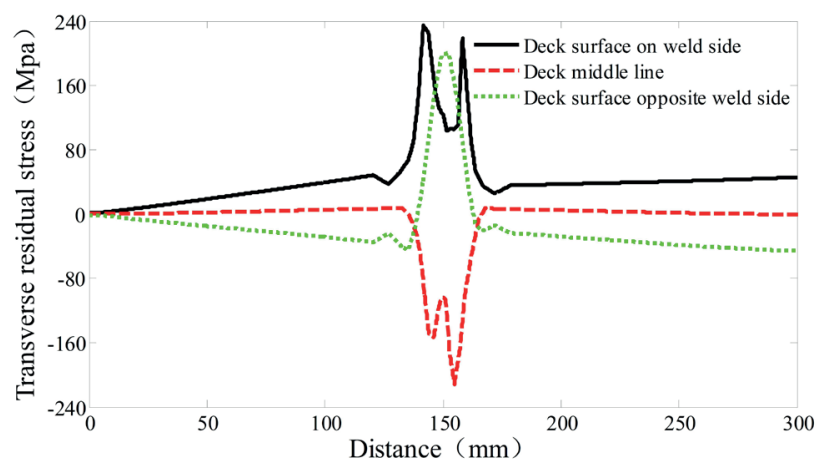

(b)

Fig. 6 Residual stress distribution of the deck-to-rib welded joints: (a) longitudinal residual stress; (b) transversal residual stress (unit: MPa) and a ribs thickness of $8 \mathrm{~mm}$ is used in experiment. In order to study the influence rule of the top deck thickness variation on the welding residual stress of the deckrib of the orthotropic steel bridge, a series of FE models the welding details of the deck-rib with the thickness of top deck ranging from 12 to $20 \mathrm{~mm}$ are established in the literature [28]. It is shown that the compressive stresses at position far from the welding joints decrease with the increase of the thickness of the top deck. Due to the different sizes of the experiment and the numerical model, the compressive residual stresses at position far from the welding joints is larger than that of the numerical simulation. As shown in Fig. 6, although the sizes of the numerical model and the experimental model are different, the numerical model results are consistent with the change of the test results; that is, the longitudinal residual stress is a tensile stress near the welding seam and a compressive stress away from the welding seam. In general, the measured points are around the simulated calculation values, and the numerical simulation results are in good agreement with the experimental data, indicating that the numerical simulation results are true and reliable.

\subsubsection{Comparison of vehicle stress between the submodel and coarse model}

Fig. 7(b) shows a comparison of the longitudinal and transverse stress time-history results under the vehicle load action (Fig. 7(a)) of Case C and Case D (a detailed description of each loading case is provided in Subsection 3.1) at the welding seam of the coarse model and the submodel. It can be seen from the figure that the stress peak at the welding seam position of the submodel under loading cases C and D agrees well with the coarse model, thus verifying the accuracy of the submodel method; therefore, the submodel is used to calculate the coupling stress of the welding residual stress and vehicle load stress in the text that follows.

\section{Analysis of the welding residual stress relaxation effect of the deck-to-rib details}

\subsection{Stress state analysis of the welding seam position under vehicle load action}

The Jiangyin Yangtze River Bridge is located in the Yangtze River delta region, which has the heaviest traffic in China, has been found that fatigue cracks occurred only after construction for nine years. Fig. 8 shows fatigue cracking in Jiangyin Bridge. Among the various types of fatigue cracks in OSDs, cracks in deck-to-rib welded joints have occurred 


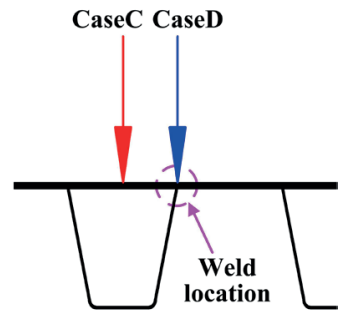

(a)

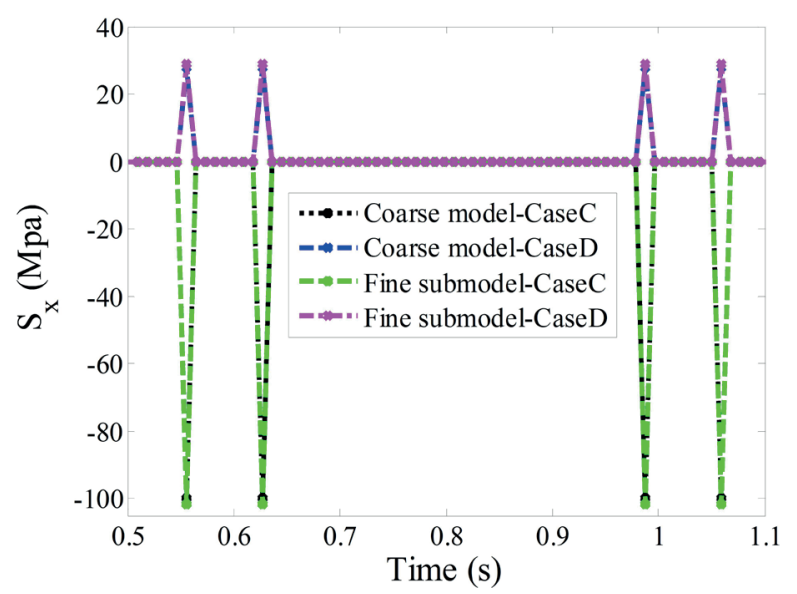

(b)

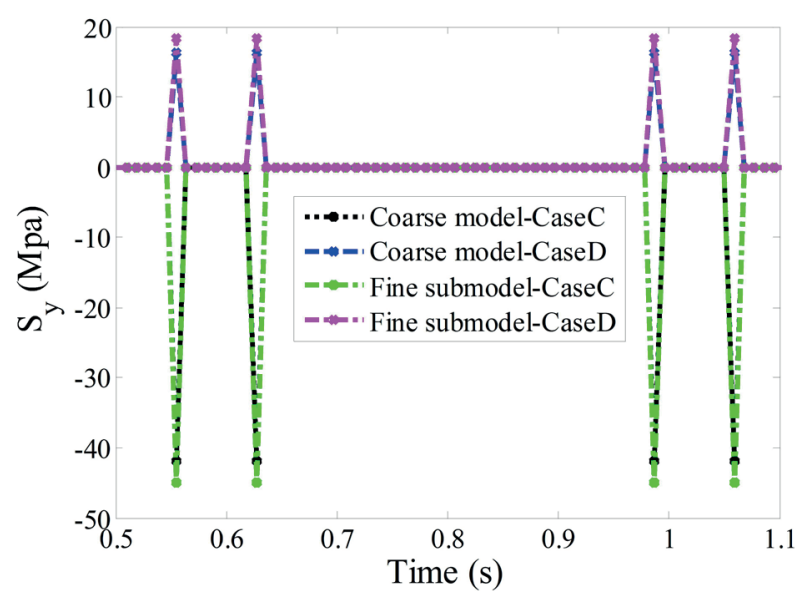

(c)

Fig. 7 Comparison between vehicle load stresses of the coarse model and submodel: (a) vehicle loading cases; (b) longitudinal residual stress $\mathrm{S}_{\mathrm{x}} ;$ (c) transverse residual stress $\mathrm{S}_{\mathrm{y}}$
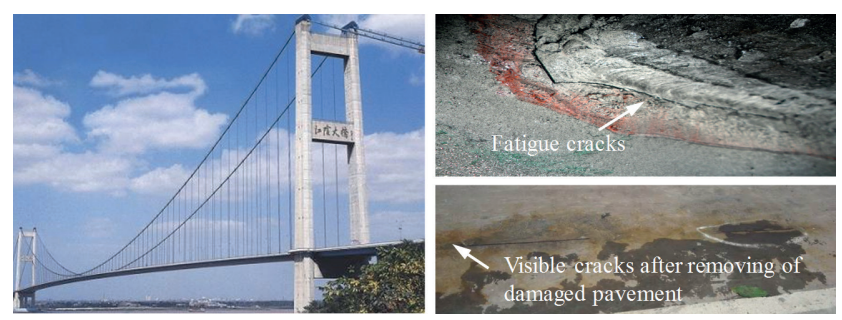

Fig. 8 Fatigue cracking in Jiangyin Yangtze River Bridge (Images by the literature 32]) most often $[2,4]$. As shown in the Fig. 8, many cracks initiated from the weld toe between the deck and rib, inducing serious damage of the orthotropic steel deck and pavement on it. In the literature [29-30], it is shown that that fatigue cracks occurred in compressive zone of various welded details in this type of bridge deck system due to welding residual tensile stress. Therefore, it is significant to consider the effect of welding residual stress for the fatigue life assessment of deck-to-rib welded joints.

To study the coupled stress state of the welding residual stress and vehicle stress at the position of the steel bridge deck-to-rib weld, Subsection 3.1 first analyzes the stress state considering only the position of the weld under the action of the vehicle. The most unfavorable loading conditions of the steel bridge deck are determined by applying vehicle loads to the shell element coarse model of a steel box girder of Jiangyin Bridge (Fig. 3) at different transverse positions. In this paper, the fatigue load calculation model selects the single-vehicle model recommended by the 'Code for the Design of Highway Steel Bridge' [31].

The axle load and distribution regulations of the model are shown in Fig. 9. Fig. 9(a) and (b) are vehicle cross a longitudinal section respectively. Z1 Z4 stands for 4 axles load respectively. Axle space is $1.2 \mathrm{~m}, 6.0 \mathrm{~m}$ and $1.2 \mathrm{~m}$ respectively from the beginning to the end. $Z$ in Fig. 9(a) stands for any one of Z1 Z4 in Fig. 9(b). The fatigue vehicle load model used for the finite element model analysis is simplified as a series of moving concentrated forces, which is applied on the surface of the orthotropic steel deck directly. Considering the randomness of vehicle travel, the transverse distance between each loading case

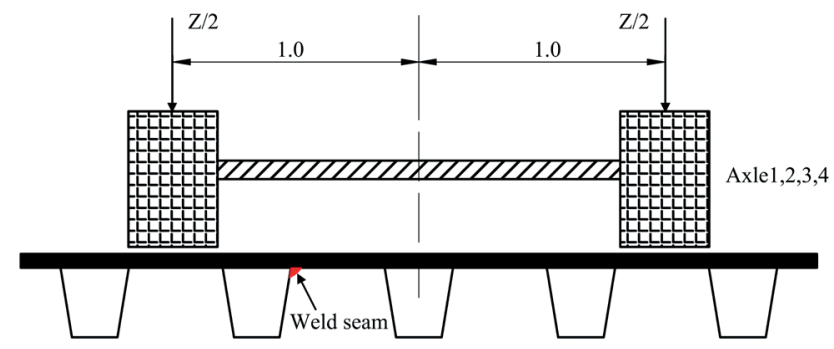

(a)

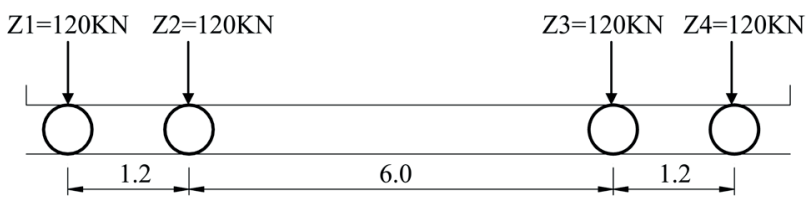

(b)

Fig. 9 Fatigue vehicle load model: (a) Vehicle cross-section; (b) Vehicle longitudinal section (unit: $\mathrm{m}$ ) 

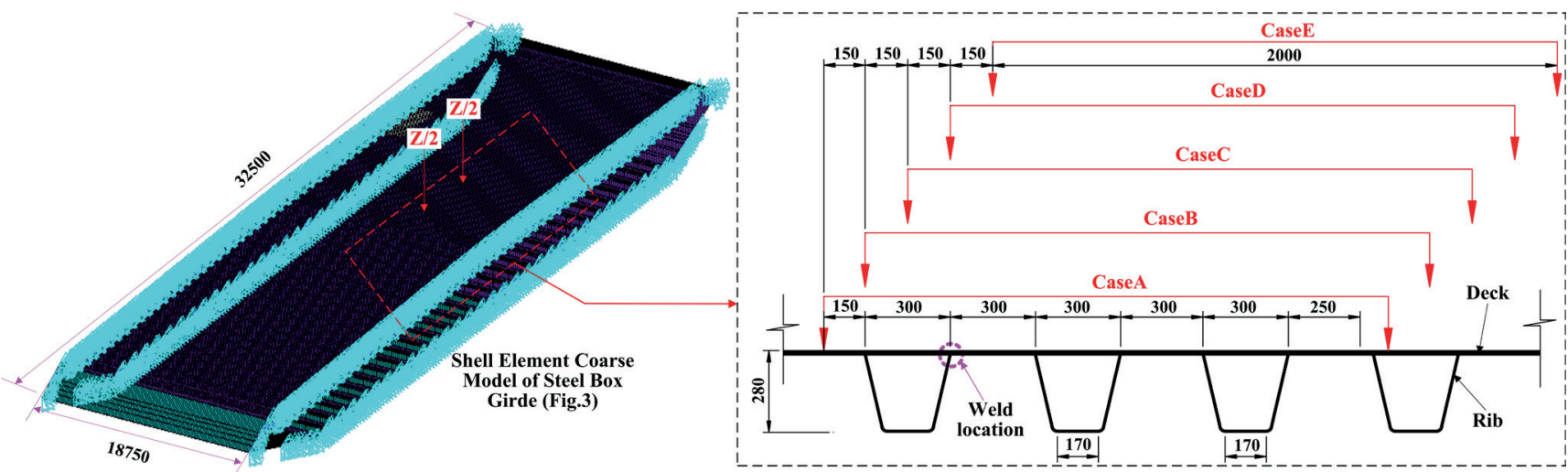

Fig. 10 Sketch of Vehicle Loading Locations

is $150 \mathrm{~mm}$, and a total of five transverse loading conditions (denoted as Case $\mathrm{A} \sim \mathrm{E}$ ) are shown in Fig. 10. The effect of vehicle load is local; that is, when the vehicle load is far away from the welding joint we need to research, it has no influence on the stress of the welding joint. Therefore, as shown in Fig. 10, the length of the segmental bridge of coarse model is $18.75 \mathrm{~m}$, which is five times as long as the diaphragm plate spacing of $3.75 \mathrm{~m}$. The width of the segmental bridge of coarse model is $32.5 \mathrm{~m}$, which is the same as the Jiangyin Bridge in practice.

Fig. 11 shows the longitudinal and transverse vehicle stress time-history curves of the weld at the positions of loading cases $\mathrm{A} \sim \mathrm{E}$. After the calculation, the stress ratio $\mathrm{R}$ of loading case D is 0 and that of all the other loading cases is $-\infty$. According to the "Code for the Design of Steel Structure of Railway Bridge" [11], when the residual stress and stress relaxation effect are not considered, the fatigue state of loading case D (where the vehicle directly acts at the position of the weld) is a tensile stress state, with longitudinal and transverse stress peaks of 27.7 MPa and 16.4 $\mathrm{MPa}$, respectively, and fatigue checking should be performed at this time. Loading cases $\mathrm{A} \sim \mathrm{C}$ and loading case $\mathrm{E}$ are compressive stress states, of which the maximum compressive stress occurs in loading case $\mathrm{C}$ (where the vehicle acts at a position $150 \mathrm{~mm}$ away from the weld), and the longitudinal and transverse stress peaks are $-99.7 \mathrm{MPa}$ and $-41.9 \mathrm{MPa}$, respectively. At this time, the influence of the compressive stress on the cumulative fatigue damage can be ignored. In Subsection 3.2, taking the maximum compressive cyclic condition $\mathrm{C}$ and the tensile cyclic condition D as examples, the coupling stress of the welding residual stress and vehicle stress and stress relaxation phenomena are analyzed, and the influence on the fatigue stress state and stress ratio is further analyzed.

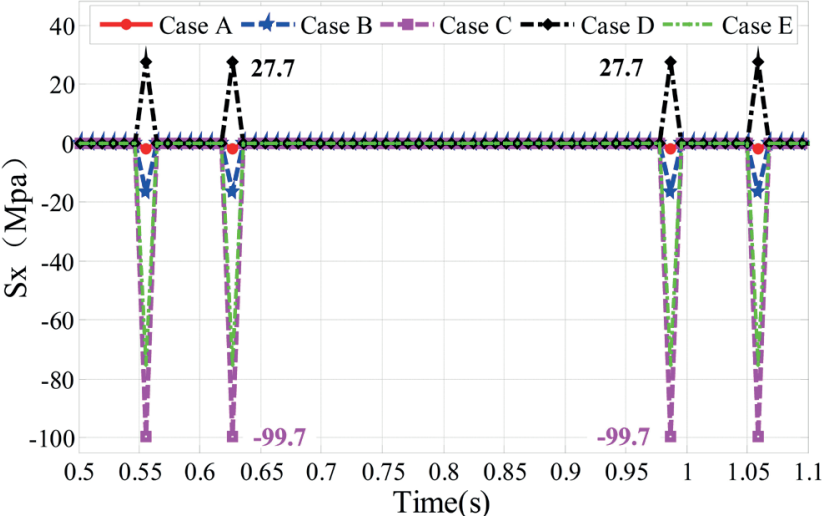

(a)

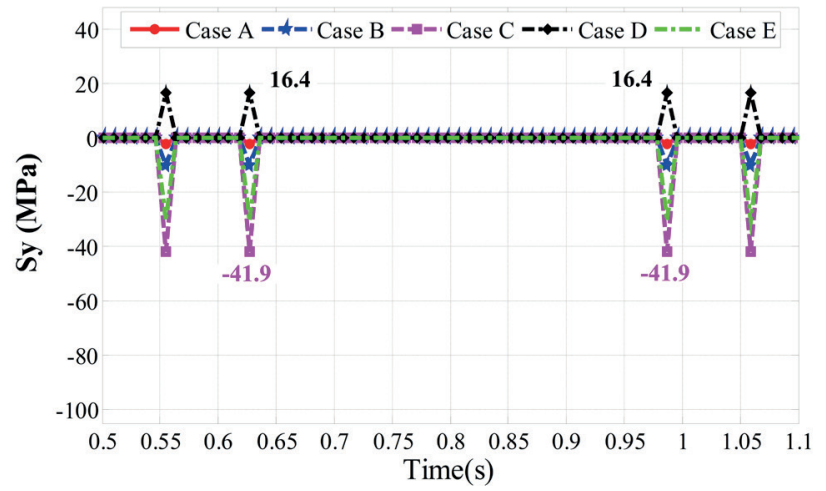

(b)

Fig. 11 Time-history curves of the vehicle load stress at the welded joint position in cases $A \sim E$ : (a) longitudinal residual stress $\mathrm{S}_{\mathrm{x}}$; (b) transverse residual stress $\mathrm{S}_{\mathrm{y}}$

\subsection{Analysis of the residual stress relaxation effect under the coupling of the welding residual stress and vehicle stress}

\subsubsection{Compressive stress cyclic loading case $\mathbf{C}$}

Fig. 12 shows the response curves of the longitudinal stress $\mathrm{S}_{\mathrm{x}}$ and the transverse stress $\mathrm{S}_{\mathrm{y}}$ at the weld toe position in loading case $\mathrm{C}$, in which the coarse model is only under the action of the vehicle and the submodel has the welding 


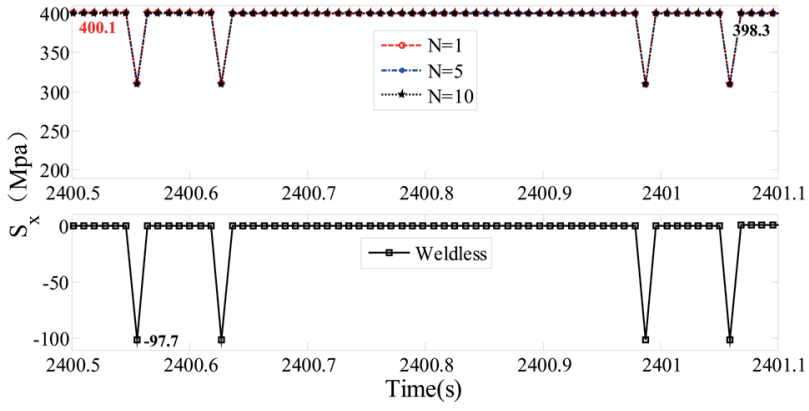

(a)

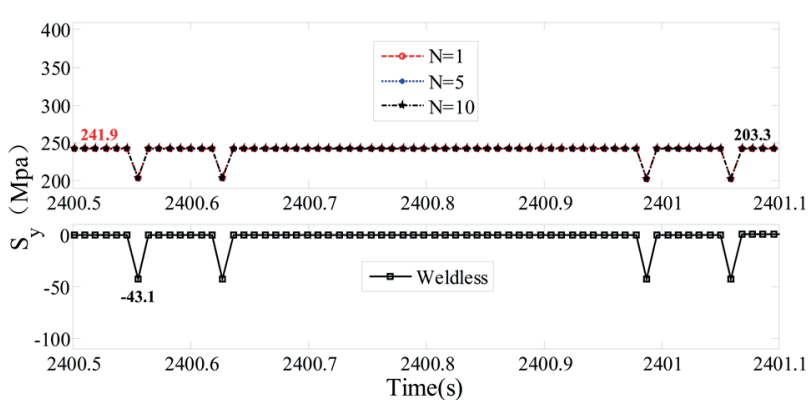

(b)

Fig. 12 Stress Response Curves at the Weld Toe in Case C:

(a) longitudinal residual stress $\mathrm{S}_{\mathrm{x}}$; (b) transverse residual stress $\mathrm{S}_{\mathrm{y}}$

residual stress and vehicle stress coupled; $\mathrm{N}$ represents the loading sequence number of the vehicle model (e.g., $\mathrm{N}=1$ means the first loading). It can be seen from Fig. 11 that the weld toe position $\mathrm{S}_{\mathrm{x}}$ is $400.1 \mathrm{MPa}$ at $2400.5 \mathrm{~s}$, which has exceeded the yield strength. After applying a mainly compressive cyclic vehicle load stress of $-97.70 \mathrm{MPa}$, the stress has decreased by $90.7 \mathrm{MPa}$; the final coupling stress was stabilized at $398.3 \mathrm{MPa}$, and the stress was only reduced by $1.8 \mathrm{MPa}$. The $\mathrm{S}_{\mathrm{y}}$ at the position of the weld toe is $241.9 \mathrm{MPa}$, and the stress is reduced by $38.6 \mathrm{MPa}$ after applying a cyclic vehicle load stress of $-43.1 \mathrm{MPa}$; at this time, the stress relaxation phenomenon did not occur. The above analysis shows that after the high-value residual tensile stress is superimposed on the mainly compressive vehicle load stress, the coupling stress at the weld toe is small, and the residual stress relaxation effect is not obvious.
To quantitatively study the influence of the coupling stress of the welding residual stress and vehicle stress on the fatigue stress state of the steel bridge deck weld toughness and qualitatively analyze its possible impact on the fatigue life, it is necessary to calculate the fatigue parameters such as the stress ratio and stress amplitude. Since the fatigue vehicle load applied in this paper is not a symmetric cyclic load, it is difficult to predict the fatigue life by the true stress at the weld toe position. Therefore, the Goodman curve [33] is introduced to convert the true stress amplitude at the welding seam to the same-lifetime equivalent stress level under symmetric cyclic loading $\left(\mathrm{R}=-1, \mathrm{~S}_{\mathrm{m}}=0\right)$. Based on the Goodman formula, the equivalent stress range $\mathrm{S}_{\mathrm{a}(\mathrm{R}=-1)}$ under symmetric cycles $\left(\mathrm{R}=-1, \mathrm{~S}_{\mathrm{m}}=0\right)$ can be expressed as

$S_{a(R=-1)}=\frac{\sigma_{s} \cdot \sigma_{\text {real }}}{\sigma_{s}-\sigma_{m}}$

In Eq. (2), $\sigma_{\text {real }}$ is the true stress range, $\sigma_{m}$ is the average stress, and $\sigma_{s}$ is the material yield strength, which is $345 \mathrm{MPa}$ for Q345 steel.

The stress response curves in Fig. 12 were processed into the respective fatigue parameters in Table 2 using Eq. (2). Since the fatigue crack initiation and propagation are directly related to the transverse stress, only the fatigue parameters corresponding to the transverse stress $\mathrm{S}_{\mathrm{y}}$ are provided. It can be seen that after considering the vehicle load stress and considering the coupling of the residual stress and vehicle load stress, the transverse true stress range $\sigma_{\text {real }}$ is decreased from 43.1 $\mathrm{MPa}$ to $39.11 \mathrm{MPa}$, a minor change, and the equivalent stress range $\mathrm{S}_{\mathrm{a}(\mathrm{R}=-1)}$ rises from $40.57 \mathrm{MPa}$ rises to $110.03 \mathrm{MPa}$, an increase by a factor of 2.7 ; the increase in the stress amplitude directly reduces the fatigue life. In addition, the stress ratio $\mathrm{R}$ changes from a negative value to a positive value, resulting in an essential change in the fatigue stress state at the weld toe, that is, the state of the compressive stress that does not require fatigue checking becomes a tensile stress state requiring a fatigue check.

Table 2 Comparison of Various Fatigue Parameters of Transverse Stress $\left(\mathrm{S}_{\mathrm{y}}\right)$ in Case C and Case D (unit: MPa)

\begin{tabular}{|c|c|c|c|c|}
\hline & & Case number & Case C & Case D \\
\hline \multirow{8}{*}{ Stress } & \multirow{2}{*}{$\Delta \sigma_{\text {real }}$} & Only considering vehicle load stress & 43.10 & 16.39 \\
\hline & & Considering the coupling effect of the welding residual stress and vehicle load stress & 39.11 & 17.76 \\
\hline & \multirow{3}{*}{$\sigma_{m}$} & Only considering vehicle load stress & -21.54 & 8.21 \\
\hline & & Considering the coupling effect of the welding residual stress and vehicle load stress & 222.37 & 248.81 \\
\hline & & Only considering vehicle load stress & 40.57 & 16.79 \\
\hline & $\mathrm{S}_{\mathrm{a}(\mathrm{R}=-1)}$ & Considering the coupling effect of the welding residual stress and vehicle load stress & 110.03 & 63.71 \\
\hline & \multirow{2}{*}{$\mathrm{R}$} & Only considering vehicle load stress & $-\infty$ & 0 \\
\hline & & Considering the coupling effect of the welding residual stress and vehicle load stress & 0.84 & 0.93 \\
\hline
\end{tabular}




\subsubsection{Tensile stress cyclic loading case D}

Fig. 13 shows the response curves of the longitudinal stress $\mathrm{S}_{\mathrm{x}}$ and transverse stress $\mathrm{S}_{\mathrm{y}}$ at the weld toe position in loading case $\mathrm{D}$, in which the coarse model is only under the action of the vehicle and the submodel, in which the welding residual stress and vehicle stress are coupled. $\mathrm{N}$ represents the loading sequence number of the vehicle model. As seen from the figure, (1) before the vehicle is applied, the weld toe position $\mathrm{S}_{\mathrm{x}}$ is $400.9 \mathrm{MPa}$ at $2400.5 \mathrm{~s}$, exceeding the yield strength. After applying the mainly tensile vehicle load stress of $27.7 \mathrm{MPa}$, the stress increased by $4.1 / 39.5 / 39.3 / 39.3 \mathrm{MPa}$; the final stress was stable at $363.4 \mathrm{MPa}$, the stress relaxation was $37.5 \mathrm{MPa}$, and $\mathrm{S}_{\mathrm{y}}$ was $242.6 \mathrm{MPa}$. After applying the mainly tensile vehicle load stress of $16.5 \mathrm{MPa}$, the stress was increased by $8.2 / 20.1 / 17.8 / 17.8 \mathrm{MPa}$; the final stress was stabilized at $239.9 \mathrm{MPa}$, and the stress relaxation was $2.7 \mathrm{MPa}$. The above analysis shows that when a high-value residual tensile stress at the weld toe is superimposed on the mainly tensile vehicle load stress, the local coupling stress state exceeds the elastic range; the longitudinal stress relaxation exceeds the vehicle stress peak, and a significant relaxation effect occurs, but the transverse stress relaxation is not obvious. (2) It can be seen from Fig. 13(b) to Fig. 13(d) that the stress relaxation effect mainly occurs in the first two loadings of the first vehicle load stress cycle, and the stress tends to be stable thereafter. (3) It can

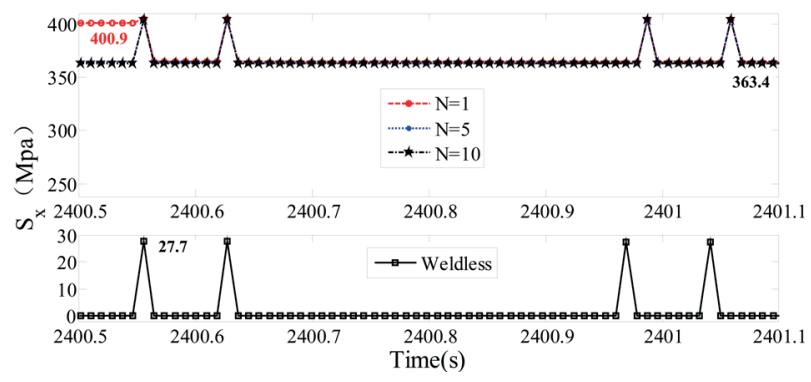

(a)

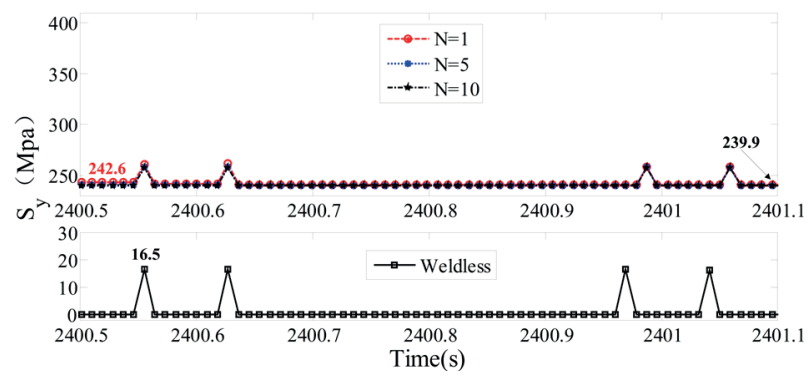

(b)

Fig. 13 Stress Response Curves at the Weld Toe in Case D: (a) longitudinal residual stress $\mathrm{S}_{\mathrm{x}}$; (b) transverse residual stress $\mathrm{S}_{\mathrm{y}}$ be seen from Table 2 that after considering the residual stress and the vehicle load stress coupling effect, although the stress ratio $\mathrm{R}$ rises from 0 to 0.93 , the fatigue stress state is still a tensile stress state, but the equivalent stress amplitude $\mathrm{S}_{\mathrm{a}(\mathrm{R}=-1)}$ increased from 16.79 $\mathrm{MPa}$ to $63.71 \mathrm{MPa}$, an increase by a factor of 3.79 ; this increase in the stress amplitude will directly reduce the fatigue life. Therefore, whether in the compressive stress cyclic loading case $\mathrm{C}$ or the tensile stress cyclic loading case $\mathrm{D}$, after considering the coupling effect of the welding residual stress and the vehicle load stress, the fatigue life at the welding seam will be reduced by different degrees.

\subsection{Influences of various factors on the stress relaxation effect}

\subsubsection{Effect of deck thickness variation on the residual stress relaxation}

To consider the influence of the variation of the deck thickness on the degree of relaxation of the welding residual stress, Subsection 3.3.1 takes loading case D as an example, establishes refined sub-models under different deck thicknesses, and performs a coupling analysis of the vehicle stress and residual stress. For convenience of expression in the following text, the deck and the longitudinal ribs are respectively abbreviated as D and L; and the D12L6 represents a model with a deck thickness of $12 \mathrm{~mm}$ and a longitudinal rib thickness of $6 \mathrm{~mm}$, and the other models are described similarly. When the thickness of the longitudinal rib is fixed at $6 \mathrm{~mm}$ and only the deck thickness changes, the longitudinal stress $\mathrm{S}_{\mathrm{x}}$ and transverse stress $\mathrm{S}_{\mathrm{y}}$ response curves of the coarse model under a vehicle load and the submodel when the welding residual stress and the vehicle stress are coupled, as shown in Fig. 14. It can be seen from the figure that (1) at $2400.5 \mathrm{~s}$, the initial longitudinal stresses at the toes of models D12L6 and D20L6 are $400.9 \mathrm{MPa}$ and $401.7 \mathrm{MPa}$, respectively. This indicates that the initial residual stress increases with the deck thickness, and the transverse stress increase is more obvious than that of the longitudinal stress. (2) The longitudinal stress relaxations at the toes of models D12L6, D16L6 and D20L6 are $37.5 \mathrm{MPa}, 37.8 \mathrm{MPa}$ and $37.3 \mathrm{MPa}$, respectively, and the transverse stress relaxations are $2.3 \mathrm{MPa}$, 5.2 $\mathrm{MPa}$ and 6.2 $\mathrm{MPa}$, respectively, indicating that the degree of influence of the increasing deck thickness on the longitudinal stress relaxation is minor, and although the transverse stress relaxation is slightly increased, the overall effect is not significant. 


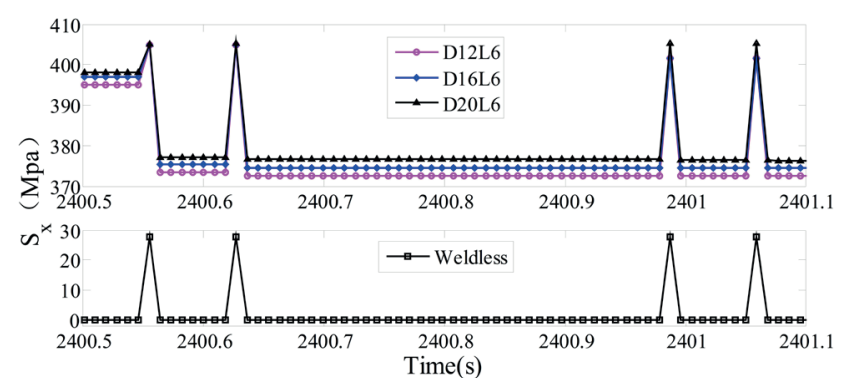

(a)

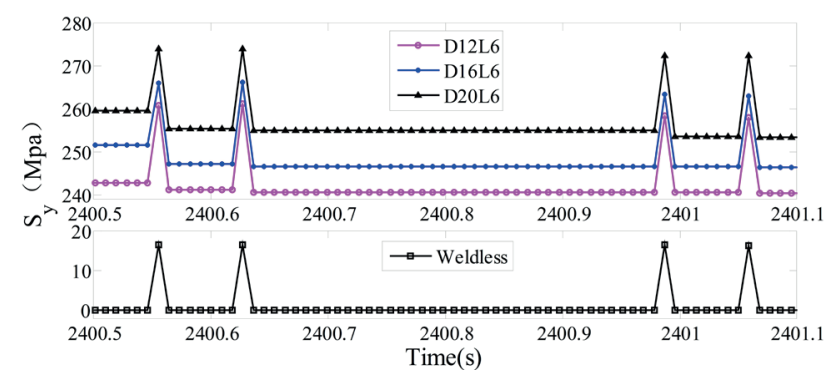

(b)

Fig. 14 Stress Response Curves at the Weld Toe in Case D:

(a) longitudinal residual stress $\mathrm{S}_{\mathrm{x}}$; (b) transverse residual stress $\mathrm{S}_{\mathrm{y}}$

3.3.2 Influence of variation of external load stress cyclic characteristics on the residual stress relaxation degree

In large marine floating structures such as ships, researchers have studied the influence of the welded joint residual stress relaxation on the fatigue strength using experimental $[23,34]$ and theoretical $[35,36]$ methods. The main factors affecting the residual stress relaxation are believed to be the initial residual stress and the externally applied load. However, the quantitative relationships among the residual stress relaxation, the initial residual stress, and the applied load of a typical welded joint, the deck-to-rib welded joint, of the steel deck of the bridge structure are still unclear. To study the relaxation law of the residual stress at the weld toe of the deck-to-rib weld detail under an external load, Subsection 3.3.2 analyzes the external load conditions of 26 different stress cyclic characteristics based on the fine submodel, mainly considering the changes of the stress range and stress ratio, as shown in Table 3.

Fig. 15 shows the relationships among the residual stress value, the initial residual stress and the external load after the coupling of the welding residual stress and the external load under 26 external loading cases. The abscissa is the ratio of sum of the initial residual stress and the applied stress to the material yield strength, and the ordinate is the ratio of the stress value that is stable after the stress relaxation to the initial residual stress. It can be seen from the figure that if the initial residual stress superimposed on the external load stress is less than the yield strength, the stress relaxation effect is not obvious. If the initial residual stress superimposed on the external load stress is greater than the yield strength, the stress relaxation will increase with the external load stress range. The change of the stress ratio has no obvious effect, and the maximum stress relaxation does not exceed $20 \%$ of the initial residual stress. According to Fig. 15, the residual stress relaxation law at the weld toe is summarized by Eq. (3), which can quantitatively predict the stress relaxation value of a welded joint by the external load stress and the initial residual stress.

$$
\begin{cases}\frac{\left(\sigma_{\text {res }}\right)_{\text {affer }}}{\left(\sigma_{\text {res }}\right)_{\text {ini }}}=-0.02 \times \frac{\left(\sigma_{\text {res }}\right)_{\text {ini }}+\sigma_{\text {app }}}{f_{y}}+1 & \frac{\left(\sigma_{\text {res }}\right)_{\text {ini }}+\sigma_{\text {app }}}{f_{y}} \leq 1 \\ \frac{\left(\sigma_{r e s}\right)_{\text {after }}}{\left(\sigma_{\text {res }}\right)_{\text {ini }}}=-0.3667 \times \frac{\left(\sigma_{\text {res }}\right)_{\text {ini }}+\sigma_{\text {app }}}{f_{y}}+1.347 & \frac{\left(\sigma_{\text {res }}\right)_{\text {ini }}+\sigma_{\text {app }}}{f_{y}}>1\end{cases}
$$

In the Eq. (3), $\left(\sigma_{\text {res }}\right)_{\text {after }}$ is the stable stress value after the coupling of the welding residual stress and the external load is considered, $\left(\sigma_{r e s}\right)_{i n i}$ is the initial residual stress, $\sigma_{a p p}$ is the external load, and $f_{y}$ is the material yield strength, which is $345 \mathrm{MPa}$ for Q345 steel. Since Eq. (3) considers the yield stress of the material, the formula is suitable for analyzing the residual stress relaxation law of different steels.

\section{Summary}

In this paper, a calculation method that couples the welding residual stress and vehicle stress based on the coupled stress analysis model is proposed. In addition, the influence of the deck thickness and external load stress cyclic characteristics on the residual stress relaxation effect is analyzed, and a formula for calculating the stress release of the residual stress in the weld toe position under an external load is summarized. Based on the above investigation, the following conclusions can be drawn:

1. Based on the deck-to-rib welded joints in an OSD, this paper establishes an analysis method for the welding residual stress relaxation effect of a steel bridge deck. The proposed method first uses a thermal-structural coupling method to simulate the initial welding residual stress generation process. Then, a submodel method is used to set the displacement boundary conditions of the local deckto-rib fine submodel. Finally, the same vehicle load stress is applied to the coarse model and the submodel to obtain the true coupled stress time-history curve of the welded detail. The analysis shows that the proposed analysis method of the welding residual stress relaxation effect of a steel bridge deck established in this paper can accurately simulate the coupling effect of the welding residual stress 
Table 3 External loading cases

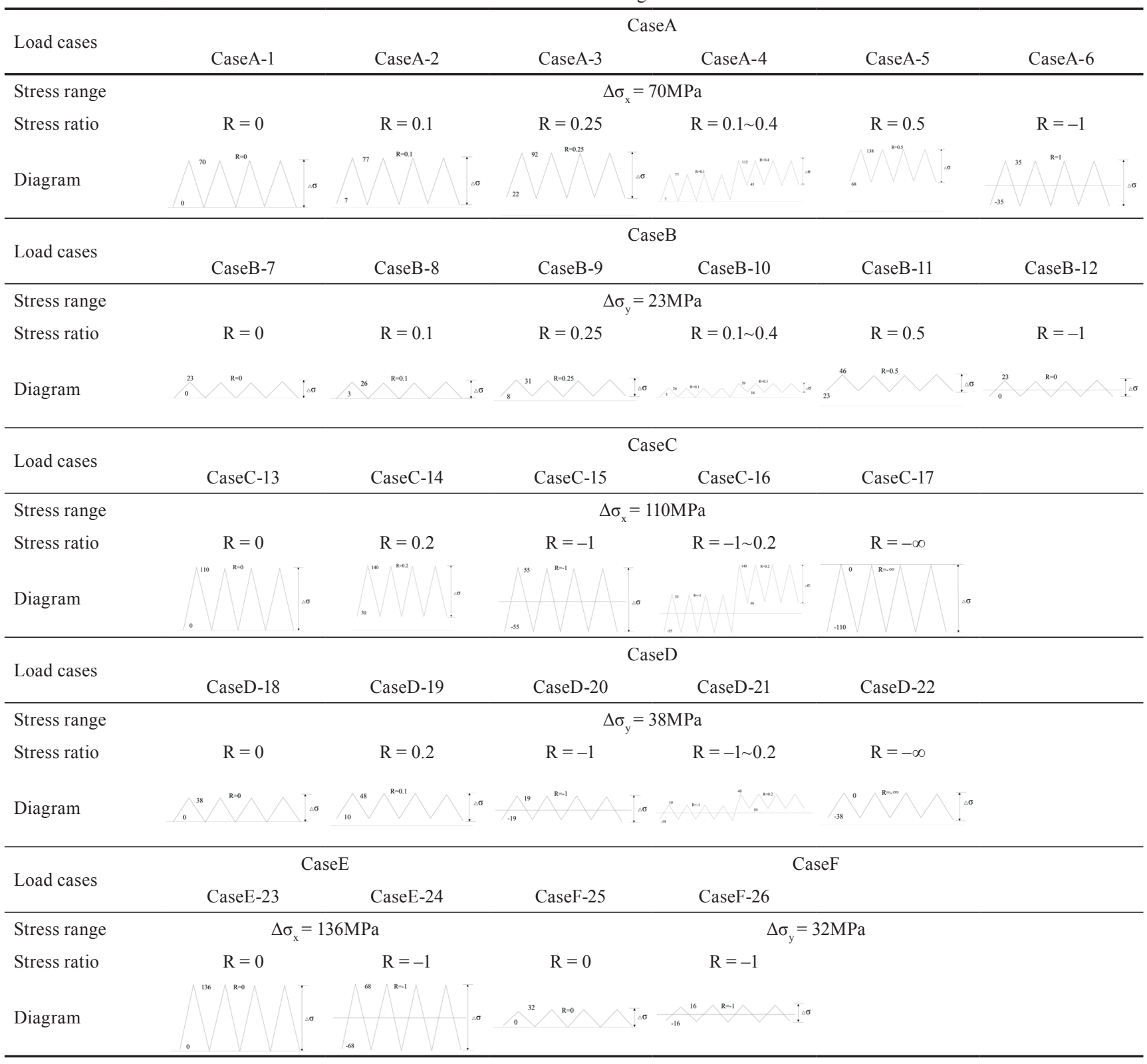

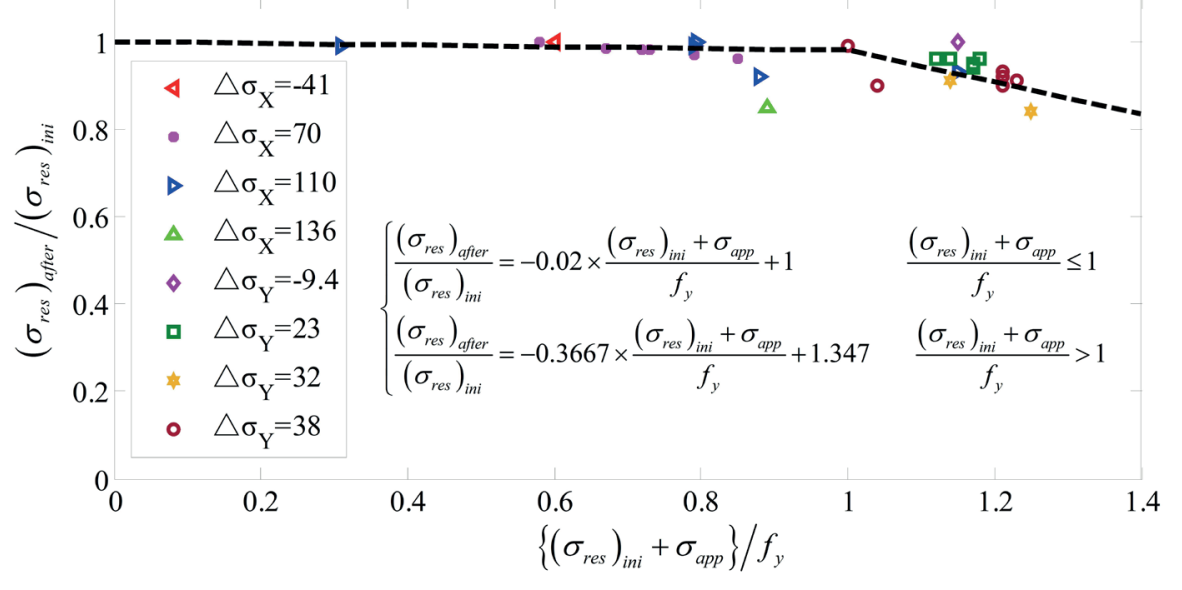

Fig. 15 Change in $\left(\sigma_{\text {res }}\right)_{\text {after }} /\left(\sigma_{\text {res }}\right)_{\text {ini }}$ due to $\left\{\left(\sigma_{\text {res }}\right)_{\text {ini }}+\sigma_{\text {app }}\right\} / f_{y}$ 
field and residual stress-vehicle stress coupling, which can be used for the analysis of the real effect of a deck-to-rib detail under the action of a vehicle load.

2 . A case analysis shows that the coupling effects of the residual stress and vehicle stress have a great influence on the fatigue life assessment. Under the influence of residual stress, the fatigue life of the welding seam under the action of a vehicle load is significantly reduced. For example, under a compressive cyclic stress, although the relaxation effect of the true stress of the weld is not obvious, the stress ratio $\mathrm{R}$ changes from $-\infty$ to a positive value and the fatigue life changes from infinite to finite. Under a mainly tensile cyclic stress, the true stress of the welding seam is obviously relaxed. The stress ratio $\mathrm{R}$ increases from 0 to 1 and the equivalent stress amplitude $\mathrm{S}_{\mathrm{a}(\mathrm{R}=-1)}$ increases, resulting in a decreased fatigue life.

3. Based on the refined coupling analysis submodel of deck-longitudinal-rib welding details, the influence of the deck thickness and external load stress cyclic characteristics on the residual stress relaxation effect is analyzed. Based on this, a calculation formula for the residual stress release at the weld toe is established. The analysis results

\section{References}

[1] Ya, S., Yamada, K., Ishikawa, T. "Fatigue Evaluation of Rib-to-Deck Welded Joints of Orthotropic Steel Bridge Deck", Journal of Bridge Engineering, 16(4), pp. 492-499, 2011.

https://doi.org/10.1061/(ASCE)BE.1943-5592.0000181

[2] Liu, R., Ji, B. H., Wang, M., Chen, C. "Numerical Evaluation of Toe-Deck Fatigue in Orthotropic Steel Bridge Deck", Journal of Performance of Constructed Facilities, 29(6), pp. 1-10, 2015. https://doi.org/10.1061/(ASCE)CF.1943-5509.0000677

[3] Song, Y. S., Ding, Y. L., Wang, G. X., Li, A. Q. "Fatigue-Life Evaluation of a High-Speed Railway Bridge with an Orthotropic Steel Deck Integrating Multiple Factors", Journal of Performance of Constructed Facilities, 30(5), pp. 1-10, 2016. https://doi.org/10.1061/(ASCE)CF.1943-5509.0000887

[4] Guo, T., Frangopol, D. M., Chen, Y. "Fatigue reliability assessment of steel bridge details integrating weigh-in-motion data and probabilistic finite element analysis", Computers \& Structures, 112-113, pp. 245-257, 2012. https://doi.org/10.1016/j.compstruc.2012.09.002

[5] Ji, B. H., Liu, R., Chen, C., Maeno, H., Chen, X. F. "Evaluation on root-deck fatigue of orthotropic steel bridge deck", Journal of Constructional Steel Research, 90, pp. 174-183, 2013. https://doi.org/10.1016/j.jcsr.2013.07.036

[6] British Standards Institution "BS 5400 Steel, concrete and composite bridges - Part 10: Code of practice for fatigue", BSI, London, UK, 1980.

[7] American Association of State Highway and Transportation Officials "Guide specifications for fatigue evaluation of existing steel bridges", AASHTO, Washington, USA, 2004. show that the transverse initial residual stress increases with the deck thickness, while the change of the deck thickness does not affect the degree of stress relaxation. When the initial residual stress superimposed on the external load stress is greater than the yield strength, the stress relaxation will increase with the external load stress range, while the change of the stress ratio has no obvious effect.

4. This paper only qualitatively analyzes the possible influence of the welding residual stress and stress ratio on the fatigue life of a steel bridge deck. How to quantitatively analyze its influence on the fatigue life and further establish an assessment method for the fatigue of a steel bridge deck considering the influence of the welding residual stress and stress ratio is the focus of the next phase of research.

\section{Acknowledgement}

The project presented in this article is supported by the Fund for Distinguished Young Scientists of Jiangsu Province (Grant. BK20190013), the Program of National Natural Science Foundation of China (no. 51978154, 51608258), and the Scientific Research Foundation of the Graduate School of Southeast University (Grant No. YBJJ1819).

[8] European Committee for Standardization "Eurocode 3 and Design of steel structures, Part 1-9: Fatigue", CEN, Brussels, Belgium, 1993.

[9] Fisher, J. W. "Fatigue and fracture in steel bridges", John Wiley and Sons, Inc., New York, NY, USA, 1984.

[10] Cheng, X. H., Fisher, J. W., Prask, H. J., Gnäupel-Herold, T., Yen, B. T., Roy, S. "Residual stress modification by post-weld treatment and its beneficial effect on fatigue strength of welded structures", International Journal of Fatigue, 25(9-11), pp. 1259-1269, 2003. https://doi.org/10.1016/j.ijfatigue.2003.08.020

[11] China Railway Major Bridge Reconnaissance and Design Institute Co., Ltd. "TB 10091-2017 and Code for Design of Steel Structure of Railway Bridge", China Railway Publishing House, Beijing, China, 2017.

[12] Savaidis, G., Malikoutsakis, M. "Advanced notch strain based calculation of S-N curves for welded components", International Journal of Fatigue, 83(1), pp. 84-92, 2016. https://doi.org/10.1016/j.ijfatigue.2015.03.003

[13] Baumgartner, J. "Enhancement of the fatigue strength assessment of welded components by consideration of mean and residual stresses in the crack initiation and propagation phases", Welding in the World, 60(3), pp. 1-12, 2016. https://doi.org/10.1007/s40194-016-0304-1

[14] Cui, C., Bu, Y. Z., Bao, Y., Zhang, Q. H. "Strain Energy-Based Fatigue Life Evaluation of Deck-to-Rib Welded Joints in OSD Considering Combined Effects of Stochastic Traffic Load and Welded Residual Stress", Journal of Bridge Engineering, 23(2), pp. 1-15, 2017. https://doi.org/10.1061/(ASCE)BE.1943-5592.0001181 
[15] Zhang, G. N., Shi, G. Y., Wang, X. D. "正交异性钢桥面板焊缝 的疲劳寿命评估方法" (Fatigue Life Evaluation Method for Weld Seams of Orthotropic Steel Bridge Deck), Chinese Journal of Solid Mechanics, 52, pp. 216-223, 2013. (in Chinese) https://doi.org/10.19636/j.cnki.cjsm42-1250/03.2013.s1.036

[16] Cui, C. "Research on Fatigue Life Evaluation and Reliability Based on Strain Energy in Deck-to-Rib Joint of Orthotropic Steel Deck", $\mathrm{PhD}$ thesis, Southwest Jiaotong University, 2018.

[17] Luo, B. L. "Relaxation Performance of Welding Residual Stress under Alternate Loadings", Master's thesis, University of Technology, 2010.

[18] Wang, Q., Liu, X. S., Yan, Z. J., Dong, Z., Yan, D. "On the mechanism of residual stresses relaxation in welded joints under cyclic loading", International Journal of Fatigue, 105, pp. 43-59, 2017. https://doi.org/10.1016/j.ijfatigue.2017.08.016

[19] Poh, K. W. "Stress-Strain-Temperature Relationship for Structural Steel", Journal of Materials in Civil Engineering, 13(5), pp. 371379, 2001.

https://doi.org/10.1061/(ASCE)0899-1561(2001)13:5(371)

[20] Teng, T. L., Fung, C. P., Chang, P. H., Yang, W. C. "Analysis of residual stresses and distortions in T-joint fillet welds", International Journal of Pressure Vessels and Piping, 78(8), pp. 523-538, 2001. https://doi.org/10.1016/S0308-0161(01)00074-6

[21] Zhang, W. J., Hao, P. F., Liu, Y., Shu, X. F. "Determination of the dynamic response of Q345 Steel Materials by Using SHPB", Procedia Engineering, 24, pp. 773-777, 2011. https://doi.org/10.1016/j.proeng.2011.11.2735

[22] Lee, C. H., Chang, K. H., Do, V. N. V. "Finite element modeling of residual stress relaxation in steel butt welds under cyclic loading", Engineering Structures, 103, pp. 63-71, 2015. https://doi.org/10.1016/j.engstruct.2015.09.001

[23] Xie, X. F., Jiang, W. C., Luo, Y., Xu, S., Gong, J. M., Tu, S. T. "A model to predict the relaxation of weld residual stress by cyclic load: Experimental and finite element modeling", International Journal of Fatigue, 95, pp. 293-301, 2017.

https://doi.org/10.1016/j.ijfatigue.2016.11.011

[24] Cui, C., Zhang, Q. H., Bao, Y., Han, S. H., Bu, Y. "Residual stress relaxation at innovative both-side welded rib-to-deck joints under cyclic loading", Journal of Constructional Steel Research, 156, pp. 9-17, 2019.

https://doi.org/10.1016/j.jcsr.2019.01.017

[25] Schajer, G. S. "Measurement of Non-Uniform Residual Stresses Using the Hole-Drilling Method. Part II - Practical Application of the Integral Method", Journal of Engineering Materials and Technology, 110(4), pp. 344-349, 1988.

https://oi.org/10.1115/1.3226060
[26] Zhao, Q., Wu, C. "U肋加劲板焊接残余应力数值模拟分析" (Numerical Analysis of Welding Residual Stress of U-rib Stiffened Plate), Engineering Mechanics, 29, pp. 262-268, 2012. (in Chinese) https://doi.org/10.6052/j.issn.1000-4750.2010.12.0935

[27] Gu, Y. "Research on welding residual stresses and deformations in steel bridge deck stiffened with U-shaped ribs", Master's thesis, Southwest Jiaotong University, China, 2011.

[28] Cao, B. Y., Ding, Y. L. "板件厚度对钢桥面板顶板纵肋焊接残余 应力的影响分析" (Influence analysis of plate thickness on welding residual stress of steel deck deck-rib), Chinese Journal of Southeast University, 46, pp. 565-571, 2016. (in Chinese) https://doi.org/10.3969/j.issn.1001-0505.2016.03.018

[29] Xiao, Z. G., Yamada, K., Ya, S., Zhao, X. L. "Stress analyses and fatigue evaluation of rib-to-deck joints in steel orthotropic decks", International Journal of Fatigue, 30, pp. 1387-1397, 2008. https://doi.org/10.1016/j.ijfatigue.2007.10.008

[30] Wang, C. S., Fu, B. N., Zhang, Q. "正交异性钢桥面板足尺疲劳 实验" (Fatigue Test on Full-scale Orthotropic Steel Bridge Deck), China Journal of Highway and Transport, 26(2), pp. 112-122, 2013. (in Chinese)

[31] Song, Y. S., Ding, Y. L. "Fatigue monitoring and analysis of orthotropic steel deck considering traffic volume and ambient temperature", Science China Technological Sciences, 56(7), pp. 1758-1766, 2013. https://doi.org/10.1007/s11431-013-5235-0

[32] CCCC Highway Consultants Co., Ltd. "JTG D64-2015 and Specifications for Design of Highway Steel Bridge", China Communications Press Co., Ltd., Beijing, China, 2015.

[33] Cheng, Y. R., Miao, L. X., Hou, B. L. "Fatigue strength", China Railway Press, Beijing, 1990.

[34] Masahiro, T., Keiji, K., Kunihiro, L. "Relaxation behavior of welding residual stresses by fatigue loading in smooth longitudinal butt welded joints", Welding in the world, 44, pp. 2-8, 2000.

[35] Zhang, B., Moan, T. "Mean stress effect on fatigue of welded joint in FPSOS", In: 25th International Conference on Offshore Mechanics and Arctic Engineering, Hamburg, Germany, 2006, pp. 403-412. https://doi.org/10.1115/OMAE2006-92056

[36] Huang, X. P., Moan, T. "Improved modeling of the effect of R-ratio on crack growth rate", International Journal of Fatigue, 29(4), pp. 591-602, 2007. https://doi.org/10.1016/j.ijfatigue.2006.07.014 